Article

\title{
Highly Efficient and Diastereoselective Construction of Sub- stituted Pyrrolidines Bearing A Quaternary Carbon Center via 1,3-Dipolar [3 + 2] Cycloaddition
}

\author{
Kaikai Wang 1,2, Yanli Li ${ }^{3}$, Yingchao Zhao ${ }^{1}$ Aili Sun ${ }^{2}$ and Rongxiang Chen 1,*and Zhanyong Wang 1,* \\ 1 School of Pharmacy, Xinxiang University, Xinxiang 453000, China. wangkaikai@xxu.edu.cn (K. Wang), \\ 1315655086@qq.com (Y.Zhao), chenrx@xxu.edu.cn (R. Chen) and zhanyongw@126.com (Z. Wang). \\ 2 Key Laboratory of Nano-carbon Modified Film Technology Engineering of Henan Province, Xinxiang \\ 453000, China. wangkaikai@xxu.edu.cn (K. Wang), sunailifly@126.com (A. Sun). \\ 3 Medical College, Xinxiang University, Xinxiang 453000, China. liyanli2005@126.com (Y. Li). \\ * Correspondence: chenrx@xxu.edu.cn (R. Chen) and zhanyongw@126.com (Z. Wang).
}

Abstract: A general approach to substituted pyrrolidines via [3 + 2] 1,3-dipolar cycloaddition between nonstabilized azomethine ylides and cyanosulfones was developed. The efficient method provides a series of substituted pyrrolidines bearing a quaternary carbon center in high yields (up to $98 \%$ ) excellent diastereoselectivities (up to $>25: 1 d r$ ) under ambient reaction conditions.

Keywords: Pyrrolidines; 1,3-dipolar cycloaddition; azomethine ylides; cyanosulfones

\section{Introduction}

The pyrrolidine ring is attractive five-membered nitrogen-containing heterocycle and appear as an important structural skeleton in a variety of natural products, biologically active alkaloids, organocatalysts and pharmaceuticals [1-3]. In fact, about 400 bioactive natural products are comprised of pyrrolizidine framework [4]. Especially, lots of drugs and bioactivated compounds include pyrrolidine motifs exhibit remarkable pharmacological activities when the pyrrolidine ring bearing a quaternary carbon at C3 position. For example, some representative examples of pyrrolidines containing quaternary stereocenter always exhibit a broad range of important biological activities (Figure 1), such as antibacterial agent [5], anthelmintic activity (Cucurbitine) [6,7], anticholesteremic and immunomodulattor (SkandF 103811) [8], ROR $\gamma \mathrm{t}$ inverse agonists [9] and so on. Therefore, the development of efficient and novel synthetic methods for functionalized pyrrolidine scaffolds bearing a quaternary carbon center at C3 position has become an attractive objective.
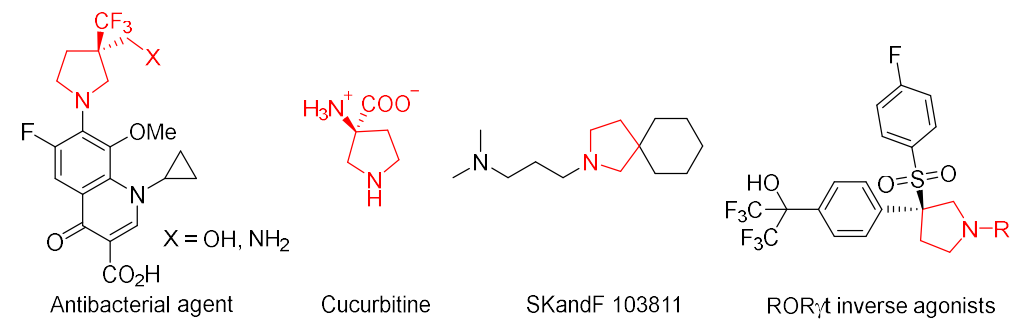

Antibacterial agent

Cucurbitine

SKandF 103811

ROR $\gamma t$ inverse agonists

Figure 1. Representative examples of biologically active nature products and pharmaceuticals containing pyrrolidine units.

To the best of our knowledge, the [3 + 2] 1,3-dipolar cycloaddition reaction of azomethine ylides with activated alkenes was proved to be one of the most effective and 
well-established methods for the chemo- and stereoselective construction of polyfunctional pyrrolidines in a single step [10-14]. In particular, azomethine ylides of non-stabilized type generated in situ from $\mathrm{N}$-(methoxymethyl)- $\mathrm{N}$-(trimethylsilylmethyl)-alkyl-amine are highly reactive intermediates [15], which reached with a diverse range of dipolarophiles to afford various nitrogen compounds via $[3+2][16-24]$ or $[3+3][25,26]$ cycloaddition reactions. Moreover, the non-stabilized azomethine ylides could take place the $\mathrm{C} \equiv \mathrm{N}$ bond of some containing cyano-group compounds (Scheme 1a) [27]. The dearomative cycloadditions between non-stabilized azomethine ylides and 3-cyanoindoles or benzofuran also had been develop to afford the corresponding cyano-group compounds bearing a quaternary carbon centre at the ring junction (scheme 1b) [28]. on the other hand, the cyano [29-32] and sulfonyl group [33-36] is a valuable functional group in organic synthesis and has shown interesting application potential in drug design and synthesis. Inspired by these previous studies, we developed that a general approach to access functionalized pyrrolidines from $\alpha, \beta$-unsaturated $\alpha, \alpha$-disubstituted aryl cyanosulfones [37,38] with non-stabilized azomethine ylides via [3+2] dipolar cycloaddition (scheme 1c). Our strategy leads to the pyrrolidines derivatives bearing a quaternary carbon center at $\mathrm{C} 3$ position with two functional groups (the cyano and sulfonyl group substituted) important for medicinal chemistry.

(a)

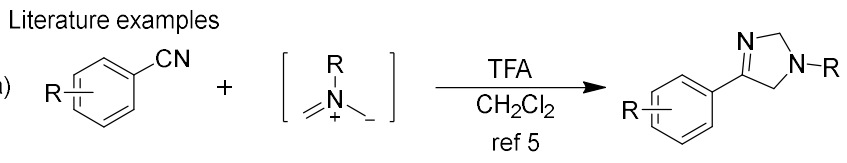

(b)
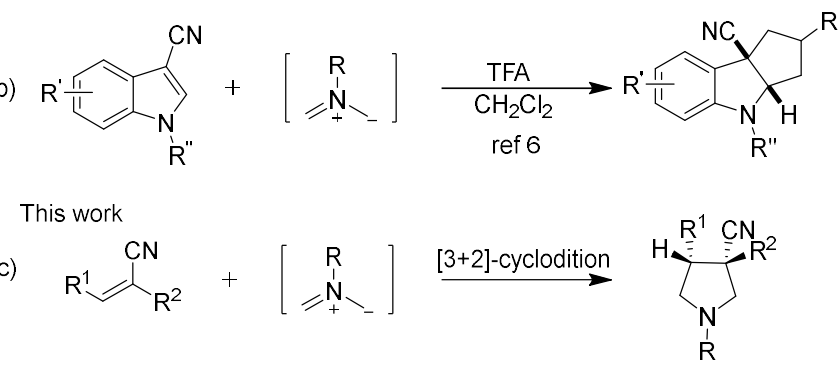

Scheme 1. [3+2]-Dipolar cycloaddition reaction of involving cyano-group compounds with non-stabilized azomethine ylides.

\section{Results}

Our investigation commenced with $\alpha$-p-toluenesulfonyl-cinnamonitrile 1a and non-stabilized azomethine ylide generated in situ from $\mathrm{N}$-(methoxymethyl)- $\mathrm{N}$-(trimethylsilyl-methyl)-benzyl-amine $2 \mathbf{a}$ in the presence of trifluoroacetic acid (TFA) as the model substrates to optimize the reaction conditions. As the results are summarized in Table 1 . To our delight, It was found that the [3+2] cycloaddition reaction proceeded smoothly and the desired cyclization product $3 \mathbf{a}$ was obtained in $90 \%$ yield with in high diastereoselective $(d r>25 ; 1)$ using $\mathrm{CH}_{2} \mathrm{Cl}_{2}$ as solvent for $6 \mathrm{~h}$ (Table 1, entry 1). In order to enhance the conversion, the time of the reaction was prolonged to $12 \mathrm{~h}$, providing the cycloadduct $3 \mathrm{a}$ in $98 \%$ yield (entry 2 ). In addition, the yield could not change when the reaction time went on prolonging to $18 \mathrm{~h}$ (entry 3 ). Subsequently, the solvent effect was investigated (entries 4-11). From among the tested solvents, the $\mathrm{CH}_{2} \mathrm{Cl}_{2}$ proved to be the best choice with respect to efficiency. When using the $\mathrm{CHCl}_{3}, \mathrm{DCE}$ or $\mathrm{CH}_{3} \mathrm{CN}$ as the solvent, the reaction gave the product in higher yield (entries 4-5 and 7). Other the solvent, such as toluene, EtOAc, Et2O, THF or dioxane, affording the product in medium yield (entries 6 and 8-11). Reducing the loading of TFA to $50 \mathrm{~mol} \%$ resulted in some loss of yield (entry 12 ). 
Table 1. Optimization of reaction conditions. ${ }^{\text {a. }}$

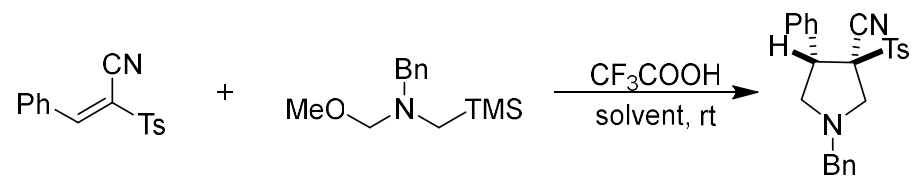

$1 \mathrm{a}$

$2 a$

$3 a$

\begin{tabular}{cccc}
\hline Entry & Solvent & Time & Yield (\%) $^{b}$ \\
\hline 1 & $\mathrm{CH}_{2} \mathrm{Cl}_{2}$ & 6 & 90 \\
2 & $\mathrm{CH}_{2} \mathrm{Cl}_{2}$ & 12 & 98 \\
3 & $\mathrm{CH}_{2} \mathrm{Cl}_{2}$ & 18 & 98 \\
4 & $\mathrm{CHCl}_{3}$ & 24 & 95 \\
5 & $\mathrm{DCE}$ & 24 & 91 \\
6 & $\mathrm{Toluene}$ & 24 & 72 \\
7 & $\mathrm{CH} \mathrm{HCN}_{3}$ & 24 & 90 \\
8 & $\mathrm{EtOAc}$ & 24 & 76 \\
9 & $\mathrm{THF}$ & 24 & 61 \\
10 & $\mathrm{Et} 2 \mathrm{O}$ & 24 & 55 \\
11 & dioxane & 24 & 58 \\
$12^{c}$ & $\mathrm{CH}_{2} \mathrm{Cl}_{2}$ & 24 & 85 \\
\hline
\end{tabular}

aUnless noted otherwise, reactions were performed with $\alpha$-p-toluenesulfonyl-cinnamonitrile 1a $(0.1$ $\mathrm{mmol}$ ) and $N$-(methoxymethyl)- $N$-(trimethyl silylmethyl)-benzyl-amine $2 \mathbf{a}(0.12 \mathrm{mmol})$, TFA (0.12 mmol, 1 equiv.) in solvent $(1.0 \mathrm{~mL})$ at rt. ${ }^{b}$ Yield of the isolated product and $d r>25: 1$ by ${ }^{1} \mathrm{H} \mathrm{NMR}$ analysis. ${ }^{c} 0.5$ equiv.TFA were used.

\section{Discussion}

Table 2. Substrate scope and limitations of the $[3+2]$ cycloaddition. $^{\text {a. }}$

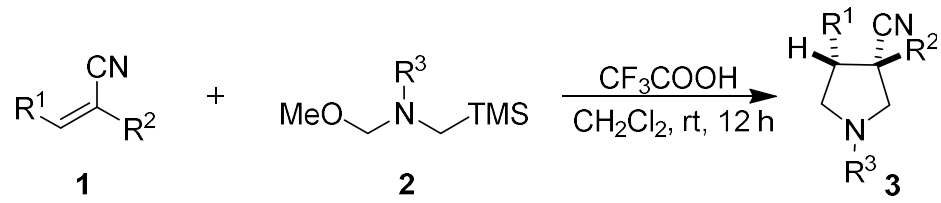

\begin{tabular}{|c|c|c|c|c|}
\hline Entry & $\mathbf{R}^{1}$ & $\mathbf{R}^{2}$ & $\mathbf{R}^{3}$ & Yield $(\%)^{b}$ \\
\hline 1 & $\mathrm{Ph}$ & Ts & $\mathrm{Bn}$ & $3 \mathbf{a}, 98$ \\
\hline 2 & $4-\mathrm{MeC}_{6} \mathrm{H}_{4-}$ & Ts & $\mathrm{Bn}$ & $3 b, 94$ \\
\hline 3 & $4-\mathrm{MeOC}_{6} \mathrm{H}_{4}-$ & Ts & $\mathrm{Bn}$ & $3 c, 95$ \\
\hline 4 & 4-BuC6 $\mathrm{H}_{4}-$ & Ts & $\mathrm{Bn}$ & $3 d, 94$ \\
\hline 5 & $4-\mathrm{FC}_{6} \mathrm{H}_{4}-$ & Ts & $\mathrm{Bn}$ & $3 \mathbf{e}, 97$ \\
\hline 6 & 4- $\mathrm{ClC}_{6} \mathrm{H}_{4}-$ & Ts & $\mathrm{Bn}$ & $3 f, 96$ \\
\hline 7 & $2-\mathrm{BrC}_{6} \mathrm{H}_{4}-$ & Ts & $\mathrm{Bn}$ & $3 g, 98$ \\
\hline $8^{c}$ & 3-BrC6 $\mathrm{H}_{4}-$ & Ts & $\mathrm{Bn}$ & $3 h, 97$ \\
\hline 9 & $4-\mathrm{BrC}_{6} \mathrm{H}_{4-}$ & Ts & $\mathrm{Bn}$ & $3 \mathbf{i}, 98$ \\
\hline 10 & $4-\mathrm{CF}_{3} \mathrm{C}_{6} \mathrm{H}_{4-}$ & Ts & $\mathrm{Bn}$ & $3 \mathbf{j}, 95$ \\
\hline 11 & $3,5-\mathrm{Cl}_{2} \mathrm{C}_{6} \mathrm{H}_{3}-$ & Ts & $\mathrm{Bn}$ & $3 \mathbf{k}, 95$ \\
\hline 12 & 2-Furyl & Ts & $\mathrm{Bn}$ & 31,92 \\
\hline 13 & 3-Thienyl & Ts & $\mathrm{Bn}$ & $3 \mathrm{~m}, 93$ \\
\hline 14 & 1-Naphthyl & Ts & $\mathrm{Bn}$ & $3 n, 96$ \\
\hline 15 & 2-Naphthyl & Ts & $\mathrm{Bn}$ & 30,96 \\
\hline 16 & $\mathrm{Ph}$ & Ts & $\mathrm{Me}$ & $3 p, 92$ \\
\hline 17 & $\mathrm{Ph}$ & $\mathrm{C}_{6} \mathrm{H}_{5} \mathrm{SO}_{2-}$ & $\mathrm{Bn}$ & $3 q, 95$ \\
\hline 18 & $\mathrm{Ph}$ & $4-\mathrm{ClC}_{6} \mathrm{H}_{4} \mathrm{SO}_{2-}$ & $\mathrm{Bn}$ & $3 \mathbf{r}, 96$ \\
\hline $19^{d}$ & $\mathrm{Ph}$ & $\mathrm{CN}$ & $\mathrm{Bn}$ & $3 s, 92$ \\
\hline $20^{\mathrm{d}}$ & $\mathrm{Ph}$ & COOEt & $\mathrm{Bn}$ & $3 t, 93$ \\
\hline 21 & $\mathrm{Ph}$ & Ac & $\mathrm{Bn}$ & $3 \mathbf{u}$, mess \\
\hline
\end{tabular}




$\begin{array}{lllll}22 & \text { Ph } & \text { Bz } & \text { Bn } & \text { 3v, mess } \\ 23 & \text { Cy } & \text { Ts } & \text { Bn } & \text { 3w, mess }\end{array}$

aUnless noted otherwise, reactions were performed with $\alpha, \beta$-unsaturated $\alpha, \alpha$-disubstituted aryl cyanosulfones $1(0.1 \mathrm{mmol}), \mathrm{N}$-(methoxymethyl)- $\mathrm{N}$-(trimethyl silylmethyl)-alkyl-amine 2 (0.12 $\mathrm{mmol})$, TFA (0.12 mmol, 1 equiv.) in $\mathrm{CH}_{2} \mathrm{Cl}_{2}(1.0 \mathrm{~mL})$ at $\mathrm{rt}$ for $12 \mathrm{~h}$. ${ }^{\text {bYield }}$ of the isolated product and $d r>25: 1$ by ${ }^{1} \mathrm{H}$ NMR analysis. ${ }^{c}$ The relative configuration of $3 \mathrm{~h}$ was determined by $\mathrm{X}$-ray analysis. The other products were assigned by analogy. ${ }^{d}$ The reaction was performed for $24 \mathrm{~h}$.

Having the optimized conditions in hand, we set out to investigate the scope and limitation of a range of conjugated arylcyanosulfones 1 for the [3+2] 1,3-dipolar cycloaddition reaction with non-stabilized azomethine ylides to provide substituted pyrrolidines. Under the optimized conditions, we were pleased to find that they all exhibited good reactivity. The results of the experiments starting from methyl-, methoxy-, tertiary butyl-, halogen-, trifluoromethyl-, substituted cyanosulfones (1)-k) and other analogues (11-o, R ${ }^{1}=$ 2-furyl, 3-thienyl, 1-naphthyl, 1-naphthyl) are presented in Table 2. The [3 + 2] cycloaddition reactions were tolerated all the screening various conjugated arylcyanosulfones 1 without any detrimental effects on the reactivity or stereoselectivity, regardless of the different positions and electronic properties of substituents and steric hindrance substituents into the aryl ring of arylcyanosulfones when the arylcyanosulfones 1 reacted smoothly with the precursor of non-stabilized azomethine ylides 2a (entries 1-15) or $\mathbf{2 b}$ (entry 16$)$. The reaction afforded the corresponding products $\mathbf{3}(\mathbf{3 a}-\mathbf{p})$ in high isolated yields (92-98\%) with excellent diastereoselectivities ( $>25: 1 d r)$. Additionally, the effect of the sulfonyl group of cyanosulfone 1q [39-40] and 1r [41-45] was studied to give the corresponding products $\mathbf{3} \mathbf{q}$ and $\mathbf{3 r}$ in $95 \%$ and $95 \%$ yields, respectively. It's worth noting that the cycloaddition reaction was also amenable to the present system, and a similar degree of diastereoselectivities was observed when the cyano group or ester group instead of the sulfonyl group (entries 19-20). However, when the substrate $\mathbf{1 u}$ and 1v [46] of the acetyl group or benzoyl group instead of the sulfonyl group and the alkylsulfonyl-substituted cyanosulfone substrate $\mathbf{1 w}$ were treated with the $[3+2]$ cycloaddition reaction under the standard condition, the reaction was disordered and offered inseparable mixture.

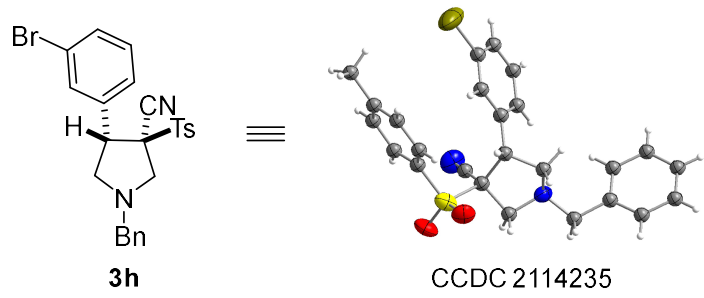

Figure 2. X-ray crystal structure of compound $3 \mathbf{h}$.

The structure and relative configuration of product 3h (CCDC 2114235) (see Figures S4 Supplementary Material) was unequivocally established by X-ray crystallographic analysis (Figure 2). For its structural details, see the Supporting information. The other products were assigned by analogy.

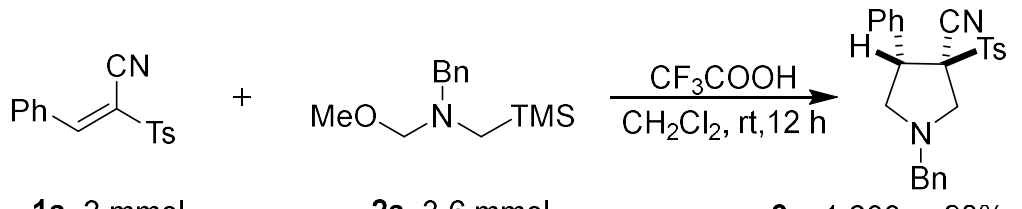
$1 \mathrm{a}, 3 \mathrm{mmol}$
$2 \mathrm{a}, 3.6 \mathrm{mmol}$
$3 a, 1.233 \mathrm{~g}, 98 \%$ yield

dr $25: 1$

Scheme 2. Scaled-up version of synthesis of substituted pyrrolidine 3a. 


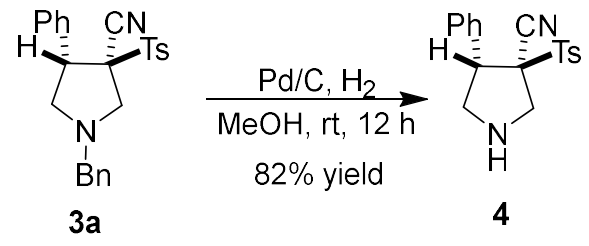

Scheme 3. Transformations of product 3a.

Finally, in order to show the broad synthetic utility of pyrrolidines for the preparation of pharmaceutically relevant molecules their gram scale experiment and subsequent transformations were studied. Firstly, $3 \mathrm{mmol}$ of $\alpha$-p-toluenesulfonyl-cinnamonitrile 1a and $3.6 \mathrm{mmol}$ of $\mathrm{N}$-(methoxymethyl)- $\mathrm{N}$-(trimethylsilyl-methyl)-benzyl-amine 2a proceeded smoothly under the standard conditions and offered compound $3 \mathrm{a}$ (1.233 $\mathrm{g})$ in $98 \%$ yield with $d r>25: 1$ (Scheme 2 ). Next, we studied the reactivity of the obtained cycloadducts for further modification of the substituted pyrrolidine motif. Cleavage of $N$-benzyl group and remove the benzyl group by hydrogenolysis of $\mathbf{3 a}$ at room temperature using $10 \% \mathrm{Pd} / \mathrm{C}$ as a catalyst afforded the target product 4 in $82 \%$ yield (Scheme 3 ).

\section{Materials and Methods}

NMR data were obtained for ${ }^{1} \mathrm{H}$ at $400 \mathrm{MHz}$, and for ${ }^{13} \mathrm{C}$ at $100 \mathrm{MHz}$. Chemical shifts were reported in ppm from tetramethylsilane with the solvent resonance as the internal standard in $\mathrm{CDCl}_{3}$ solution. ESI HRMS was recorded on a Waters SYNAPT G2. Column chromatography was performed on silica gel (200-300 mesh) eluting with ethyl acetate/petroleum ether. TLC was performed on glass-backed silica plates. UV light, I2, and solution of potassium permanganate were used to visualize products. All chemicals were used without purification as commercially available unless otherwise noted. Petroleum ether and ethyl acetate were distilled. THF was freshly distilled from sodium/benzophenone. Unless otherwise noted, experiments involving moisture and/or air sensitive components were performed under a positive pressure of argon in oven-dried glassware equipped with a rubber septum inlet. Dried solvents and liquid reagents were transferred by oven-dried syringes.

$\alpha, \beta$-unsaturated $\alpha, \alpha$-disubstituted aryl cyanosulfones 1a-r [37] and benzylidenemalononitrile $1 s \quad[39,40]$ and ethyl $\alpha$-cyanocinnamate $1 t$ [42-44] and $\alpha$-Cyano- $\alpha, \beta$-unsaturated ketones $\mathbf{1 u - v}$ [45] were prepared according to the literature procedures. The $\alpha, \beta$-unsaturated $\alpha, \alpha$-disubstituted aryl cyanosulfones 1 (0.1 mmol), $N$-(methoxymethyl)- $N$-(trimethyl silylmethyl)alkylamine $2(0.12 \mathrm{mmol})$, and the TFA $(0.12 \mathrm{mmol})$ were dissolved in $\mathrm{CH}_{2} \mathrm{Cl}_{2}(1.0 \mathrm{~mL})$. Then the solution was stirred at $\mathrm{rt}$ for 12 h. After completion, the mixture was directly purified by column chromatography on silica gel eluting with petroleum ether/ethyl acetate (10:1 to 5:1) to afford the product 3 .

\section{Conclusions}

In summary, we have successfully shown that $\alpha, \beta$-unsaturated $\alpha, \alpha$-disubstituted aryl cyanosulfones behave as $\mathrm{C}=\mathrm{C}$ dipolarophiles when reacted with a non-stabilized azomethine ylides generated in situ as electron-rich enriched 1,3-dipoles. The transformation features excellent diastereoselectivities, broad substrate scope, low cost of reagents, and convenient operation. The [3+2] cycloaddition provides an efficient protocol for affording novel and substituted pyrrolidines bearing a quaternary centre from easily available substrates in high yields (up to 98\%) with excellent diastereoselectivities (>25:1 $d r$ ) without any metal catalysts. The potential synthetic utility and practicality of the approach were also highlighted by the gram-scale experiment and the synthetic transformation of the product into other heterocyclic compounds. The further application of this strategy is presently under bioactive investigation in our laboratory. 
Supplementary Materials: The following are available online. Figure S1: Some new substrates of $\alpha, \beta$-unsaturated $\alpha, \alpha$-disubstituted aryl cyanosulfones, Figure S2: General procedure for [3+2] dipolar cycloaddition, Figure S3: Transformations of product 3a. Figure S4: X-ray crystal structure of compound 3 h. Figure S5: NMR spectra.

Author Contributions: K.K. Wang, Y.L. Li and Y.C. Zhao participated in the synthesis, purification and characterization of the new compound. R.X. Chen and A.L. Sun participated in the interpretation of spectroscopy of new compounds and the review of the manuscript. R.X. Chen and Z.Y. Wang participated in the interpretation of the results, writing, revision and correspondence to the journal of molecules until the manuscript was accepted. All authors have read and agreed to the published version of the manuscript.

Funding: This research was funded by the National Natural Science Foundation of China (Nos.21801214), Key Scientific Research Project of Colleges and Universities in Henan Province of China (Nos.18A150014 and 20B150019), the Natural Science Foundation of Henan Province (Nos.202300410016), the Program for Youth Backbone Teacher Training in University of Henan Province (2021GGJS163), Funding of National College Students Innovation and Entrepreneurship Training Program (202111071025 and 202111071021), Key Scientific and Technological Project of Xinxiang (21ZD010) and this work is supported by PhD research start-up foundation of Xinxiang University (1366020133).

Institutional Review Board Statement: Not applicable.

Informed Consent Statement: Not applicable.

Data Availability Statement: Data is contained within the article or supplementary material.

Acknowledgments: We are grateful for the financial support from the National Natural Science Foundation of China (Nos.21801214), Key Scientific Research Project of Colleges and Universities in Henan Province of China (Nos.18A150014 and 20B150019), the Natural Science Foundation of Henan Province (Nos.202300410016), the Program for Youth Backbone Teacher Training in University of Henan Province (2021GGJS163), Funding of National College Students Innovation and Entrepreneurship Training Program (202111071025 and 202111071021), Key Scientific and Technological Project of Xinxiang (21ZD010) and this work is supported by PhD research start-up foundation of Xinxiang University (1366020133).

Conflicts of Interest: The authors declare no conflict of interest. The funders had no role in the design of the study; in the collection, analyses, or interpretation of data; in the writing of the manuscript, or in the decision to publish the results.

Sample Availability: Samples of the compounds are available from the authors.

\section{References}

1. Meyers, M. J.; Liu, J.; Liu, Z.; Ma, H.; Dai, L.; Adah, D.; Zhao, S.; Li, X.; Liu, X.; Lu, Y.; Huang, Y.; Tu, Z.; Chen, X.; Tortorella, M. D., 4-Aryl Pyrrolidines as Novel Orally Efficacious Antimalarial Agents. Part 2: 2-Aryl-N-(4-arylpyrrolidin-3-yl)acetamides. ACS. Med. Chem. Lett. 2019, 10, 966-971. doi: 10.1021/acsmedchemlett.9b00123.

2. Li, J.; Ye, Y.; Zhang, Y., Cycloaddition/annulation strategies for the construction of multisubstituted pyrrolidines and their applications in natural product synthesis. Org. Chem. Front. 2018, 5, 864-892. doi: 10.1039/c7qo01077j.

3. An, F.; Maji, B.; Min, E.; Ofial, A. R.; Mayr, H., Basicities and Nucleophilicities of Pyrrolidines and Imidazolidinones Used as Organocatalysts. J. Am. Chem. Soc. 2020, 142, 1526-1547. doi: 10.1021/jacs.9b11877.

4. Thu Huong, D. T.; Martin, M.-T.; Litaudon, M.; Sévenet, T.; Païs, M., Pyrrolizidine Alkaloids from Amphorogyne spicata. J. Nat. Prod. 1998, 61, 1444-1446. doi: 10.1021/np980225b.

5. Cheng, X.; Yan, D.; Dong, X.-Q.; Wang, C.-J., Chiral Trifluoromethylated Pyrrolidines via Cu-Catalyzed Asymmetric 1,3-Dipolar Cycloaddition. Asian J. Org. Chem. 2020, 9, 1567-1570. doi: 10.1002/ajoc.202000295.

6. Buev, E. M.; Smorodina, A. A.; Moshkin, V. S.; Sosnovskikh, V. Y., Nonstabilized azomethine ylides in the synthesis of aryl cucurbitine derivatives. Tetrahedron Lett. 2019, 60, 649-652. doi: 10.1016/j.tetlet.2019.01.047.

7. Yamaberi, Y.; Eto, R.; Umeno, T.; Kato, T.; Doi, M.; Yokoo, H.; Oba, M.; Tanaka, M., Synthesis of (S)-(-)-Cucurbitine and Conformation of Its Homopeptides. Org. Lett. 2021, 23, 4358-4362. doi: 10.1021/acs.orglett.1c01291.

8. Yin, X.; Feng, S.; Chi, Y.; Liu, J.; Sun, K.; Guo, C.; Wu, Z., Estrogen-functionalized liposomes grafted with glutathione-responsive sheddable chotooligosaccharides for the therapy of osteosarcoma. Drug. Deliv. 2018, 25, 900-908. doi: 10.1080/10717544.2018.1458920.

9. Duan, J. J. W.; Lu, Z.; Jiang, B.; Stachura, S.; Weigelt, C. A.; Sack, J. S.; Khan, J.; Ruzanov, M.; Galella, M. A.; Wu, D.-R.; Yarde, M.; Shen, D.-R.; Shuster, D. J.; Borowski, V.; Xie, J. H.; Zhang, L.; Vanteru, S.; Gupta, A. K.; Mathur, A.; Zhao, Q.; Foster, W.; 
Salter-Cid, L. M.; Carter, P. H.; Dhar, T. G. M., Structure-based Discovery of Phenyl (3-Phenylpyrrolidin-3-yl)sulfones as Selective, Orally Active ROR $\gamma \mathrm{t}$ Inverse Agonists. ACS. Med. Chem. Lett. 2019, 10, 367-373. doi: 10.1021/acsmedchemlett.9b00010.

10. Pandey, G.; Banerjee, P.; Gadre, S. R., Construction of enantiopure pyrrolidine ring system via asymmetric 3+2 -cycloaddition of azomethine ylides. Chem. Rev. 2006, 106, 4484-4517. doi: 10.1021/cr050011g.

11. Narayan, R.; Potowski, M.; Jia, Z.-J.; Antonchick, A. P.; Wadmann, H., Catalytic Enantioselective 1,3-Dipolar Cycloadditions of Azomethine Ylides for Biology-Oriented Synthesis. Acc. Chem. Res. 2014, 47, 1296-1310. doi: 10.1021/ar400286b.

12. Bdiri, B.; Zhao, B.-J.; Zhou, Z.-M., Recent advances in the enantioselective 1,3-dipolar cycloaddition of azomethine ylides and dipolarophiles. Tetrahedron: Asymmetry 2017, 28, 876-899. doi: 10.1016/j.tetasy.2017.05.010.

13. Singh, M. S.; Chowdhury, S.; Koley, S., Progress in 1,3-dipolar cycloadditions in the recent decade: an update to strategic development towards the arsenal of organic synthesis. Tetrahedron 2016, 72, 1603-1644. doi: 10.1016/j.tet.2016.02.031.

14. Fang, X.; Wang, C.-J., Catalytic asymmetric construction of spiropyrrolidines via 1,3-dipolar cycloaddition of azomethine ylides. Org. Biomol. Chem. 2018, 16, 2591-2601. doi: 10.1039/C7OB02686B.

15. Buev, E. M.; Moshkin, V. S.; Sosnovskikh, V. Y., Reagents for Storage and Regeneration of Nonstabilized Azomethine Ylides: Spiroanthraceneoxazolidines. Org. Lett. 2016, 18, 1764-1767. doi: 10.1021/acs.orglett.6b00475.

16. Savych, V. I.; Mykhalchuk, V. L.; Melnychuk, P. V.; Isakov, A. O.; Savchuk, T.; Timoshenko, V. M.; Siry, S. A.; Pavlenko, S. O.; Kovalenko, D. V.; Hryshchuk, O. V.; Reznik, V. A.; Chalyk, B. A.; Yarmolchuk, V. S.; Rusanov, E. B.; Mykhailiuk, P. K., Bicyclic Pyrrolidines for Medicinal Chemistry via $[3+2]$-Cycloaddition. J. Org. Chem. 2021, 86, 13289-13309. doi: 10.1021/acs.joc.1c01327.

17. Obydennov, D. L.; Steben'kov, V. D.; Obydennov, K. L.; Usachev, S. A.; Moshkin, V. S.; Sosnovskikh, V. Y., Reactions of 4-Pyrones with Azomethine Ylides as a Chemo-selective Method for the Construction of Multisubstituted Pyrano 2,3-c pyrrolidines. Synthesis-stuttgart. 2021, 53, 2621-2631. doi: 10.1055/s-0040-1706032.

18. Buev, E. M.; Stepanov, M. A.; Moshkin, V. S.; Sosnovskikh, V. Y., Synthesis of 6,12-Methanodibenzo[c,f]azocines and 4-Aryltetrahydroisoquinolines from Aromatic Aldehydes. Org. Lett. 2020, 22, 631-635. doi: 10.1021/acs.orglett.9b04401.

19. Zimmermann, S.; Akbarzadeh, M.; Otte, F.; Strohmann, C.; Sankar, M. G.; Ziegler, S.; Pahl, A.; Sievers, S.; Kumar, K., A Scaffold-Diversity Synthesis of Biologically Intriguing Cyclic Sulfonamides. Chem. Eur. J. 2019, 25, 15498-15503. doi: 10.1002/chem.201904175.

20. Wang, K.-K.; Li, Y.-L.; Ma, G.-Y.; Yi, M.-H.; Zhu, B.-K., Highly Efficient and Diastereoselective Construction of Tricyclic Pyrrolidine-Fused Benzo[b]thiophene 1,1-dioxide Derivatives via 1,3-Dipolar [3 + 2] Cycloaddition. J. Heterocyclic Chem. 2019, 56, 2274-2280. doi: 10.1002/jhet.3591.

21. Thierry, T.; Lebargy, C.; Pfund, E.; Lequeux, T., Photoinduced Nonstabilized Azomethine Ylide Formation for the Preparation of Fluorine Containing Pyrrolidines. J. Org. Chem. 2019, 84, 5877-5885. doi: 10.1021/acs.joc.9b00244.

22. Laha, J. K.; Jethava, K. P., Access to Imidazolidine-Fused Sulfamidates and Sulfamides Bearing a Quaternary Center via 1,3-Dipolar Cycloaddition of Nonstabilized Azomethine Ylides. J. Org. Chem. 2017, 82, 3597-3604. doi: 10.1021/acs.joc.7b00116.

23. Buev, E. M.; Moshkin, V. S.; Sosnovskikh, V. Y., Nonstabilized Azomethine Ylides in the Mannich Reaction: Synthesis of 3,3-Disubstituted Pyrrolidines, Including Oxindole Alkaloids. J. Org. Chem. 2017, 82, 12827-12833. doi: 10.1021/acs.joc.7b02193.

24. Izquierdo, C.; Esteban, F.; Ruano, J. L. G.; Fraile, A.; Alemán, J., Asymmetric Synthesis of 1,2-Diamines bearing Tetrasubstituted Centers from Nonstabilized Azomethine Ylides and N-Sulfinylketimines under Brønsted Acid Catalysis. Org. Lett. 2016, 18, 92-95. doi: 10.1021/acs.orglett.5b03251.

25. Wang, K.-K.; Li, Y.-L.; Wang, Z.-Y.; Hu, M.-W.; Qiu, T.-T.; Zhu, B.-K., Cross 1,3-dipolar cycloadditions of C, N- cyclic azomethine imines with an $\mathrm{N}$ - benzyl azomethine ylide: facile access to fused tricyclic 1,2,4-hexahydrotriazines. Org. Biomol. Chem. 2019, 17, 244-247. doi: 10.1039/c8ob02932f.

26. Li, S.-n.; Yu, B.; Liu, J.; Li, H.-1.; Na, R., Bronsted Acid or Lewis Acid Catalyzed 3+3 Cycloaddition of Azomethine Imines with N-Benzyl Azomethine Ylide: A Facile Access to Bicyclic N-Heterocycles. Synlett 2016, 27, 282-286. doi: 10.1055/s-0035-1560506.

27. Beuvin, M.; Manneveau, M.; Diab, S.; Picard, B.; Sanselme, M.; Piettre, S. R.; Legros, J.; Chataigner, I., New synthesis of imidazole derivatives from cyanobenzenes. Tetrahedron Lett. 2018, 59, 4487-4491. doi: 10.1016/j.tetlet.2018.11.020.

28. Manneveau, M.; Tanii, S.; Gens, F.; Legros, J.; Chataigner, I., Dearomatization of 3-cyanoindoles by $(3+2)$ cycloaddition: from batch to flow chemistry. Org. Biomol. Chem. 2020, 18, 3481-3486. doi: 10.1039/D0OB00582G.

29. Pimparkar, S.; Koodan, A.; Maiti, S.; Ahmed, N. S.; Mostafa, M. M. M.; Maiti, D., C-CN bond formation: an overview of diverse strategies. Chem. Commun. 2021, 57, 2210-2232. doi: 10.1039/D0CC07783F.

30. Schörgenhumer, J.; Waser, M., New strategies and applications using electrophilic cyanide-transfer reagents under transition metal-free conditions. Org. Chem. Front. 2016, 3, 1535-1540. doi: 10.1039/C6QO00390G.

31. Ohmatsu, K.; Morita, Y.; Kiyokawa, M.; Ooi, T., Catalytic Asymmetric Cyanoalkylation of Electron-Deficient Olefins with Potassium Cyanide and Alkyl Halides. J. Am. Chem. Soc. 2021, 143, 11218-11224. doi: 10.1021/jacs.1c05380.

32. Cui, T.; Zhan, Y.; Dai, C.; Lin, J.; Liu, P.; Sun, P., Electrochemical Oxidative Regioselective C-H Cyanation of Imidazo[1,2-a]pyridines. J. Org. Chem. 2021. doi: 10.1021/acs.joc.0c03026.

33. Xu, Z.-Q.; Wang, W.-B.; Zheng, L.-C.; Li, L.; Duan, L.; Li, Y.-M., Iodine-mediated aminosulfonylation of alkenyl sulfonamides with sulfonyl hydrazides: synthesis of sulfonylmethyl piperidines, pyrrolidines and pyrazolines. Org. Biomol. Chem. 2019, 17, 9026-9038. doi: 10.1039/c9ob01847f.

34. Aziz, J.; Messaoudi, S.; Alami, M.; Hamze, A., Sulfinate derivatives: dual and versatile partners in organic synthesis. Org. Biomol. Chem. 2014, 12, 9743-9759. doi: 10.1039/C4OB01727G. 
35. Fang, Y.; Luo, Z.; Xu, X., Recent advances in the synthesis of vinyl sulfones. RSC Adv. 2016, 6, 59661-59676. doi: 10.1039/C6RA10731A.

36. Chen, X.; Hussain, S.; Parveen, S.; Zhang, S.; Yang, Y.; Zhu, C., Sulfonyl Group-Containing Compounds in the Design of Potential Drugs for the Treatment of Diabetes and Its Complications. Curr. Med. Chem. 2012, 19, 3578-3604.

37. Rajkumar, S.; Shankland, K.; Goodman, J. M.; Cobb, A. J. A., Organocatalytic Domino Reaction of Cyanosulfones: Access to Complex Cyclohexane Systems with Quaternary Carbon Centers. Org. Lett. 2013, 15, 1386-1389. doi: 10.1021/ol400356k.

38. Nemcsok, T.; Rapi, Z.; Bagi, P.; Guan, Y. H.; Orbán, I.; Keglevich, G.; Bakó, P., Enantioselective cyclopropanation of conjugated cyanosulfones using carbohydrate-based crown ether catalysts. Tetrahedron 2020, 76, 130965-13974. doi: 10.1016/j.tet.2020.130965.

39. Jang, Y.-J.; Chen, Y.-S.; Lee, C.-J.; Chen, C.-H.; Reddy, G. M.; Ko, C.-T.; Lin, W., Asymmetric Organocatalytic Synthesis of Highly Substituted Cyclohexenols by Domino Double-Michael Reactions of 1-Hydroxy-1,4-dien-3-ones and 2-Alkylidenemalononitriles. Eur. J. Org. Chem. 2015, 2015, 2066-2074. doi: 10.1002/ejoc.201403677.

40. Patil, N. T.; Huo, Z.; Yamamoto, Y., Palladium-catalyzed decarboxylative aza-Michael addition-allylation reactions between allyl carbamates and activated olefins. Generation of quaternary carbon adjacent to secondary amine carbon center. J. Org. Chem. 2006, 71, 6991-6995. doi: 10.1021/jo061110c.

41. Champetter, P.; Castillo-Aguilera, O.; Taillier, C.; Briere, J.-F.; Dalla, V.; Oudeyer, S.; Comesse, S., N-Alkoxyacrylamides in Domino Reactions: Catalytic and Stereoselective Access to delta-Lactams. Eur. J. Org. Chem. 2019, 2019, 7703-7710. doi: 10.1002/ejoc.201901528.

42. Jin, T.-S.; Wang, X.; Liu, L.-B.; Li, T.-S., Clean Synthesis of Ethyl $\alpha$-Cyanocinnamates Catalyzed by Hexadecyltrimethyl Ammonium Bromide in Aqueous Media. J. Chem. Res. 2006, 37, 346-347. doi: 10.1002/chin.200645075.

43. Nayak, S.; Panda, P.; Bhakta, S.; Mishra, S. K.; Mohapatra, S., Current advances of organocatalytic Michael-Michael cascade reaction in the synthesis of highly functionalized cyclic molecules. RSC Adv. 2016, 6, 96154-96175. doi: 10.1039/c6ra21191g.

44. Wang, S. X.; Li, J. T.; Yang, W. Z.; Yin, Y. H.; Xie, Z. H., Solvent-free synthesis of ethyl alpha-cyanocinnamates catalyzed by $\mathrm{K}_{2} \mathrm{O}-\mathrm{Al}_{2} \mathrm{O}_{3}$ using grinding method. Synthetic. Commun. 2004, 34, 829-834. doi: 10.1081/scc-120028355.

45. Wang, K.-K.; Wang, P.; Ouyang, Q.; Du, W.; Chen, Y.-C., Substrate-controlled switchable asymmetric annulations to access polyheterocyclic skeletons. Chem. Commun. 2016, 52, 11104-11107. doi: 10.1039/c6cc06148f. 